\title{
Improved Control Strategy Based on Space Vectors for Suppressing Grid-Side Current Harmonics in Three-Phase Current Source Rectifiers with a Hybrid Switch
}

\author{
Yan $\mathrm{Xu}^{\dagger}$, Guang-xiang Lu*, Li-jie Jiang ${ }^{* *}$, and Gui-Ping $\mathrm{Yi}^{* * *}$ \\ $\dagger^{* *}$ Department of Electrical Engineering, Southeast University, Nanjing, China \\ ${ }^{* *}$ Monlithicpower System Inc., Hangzhou, China \\ ${ }^{* * *}$ sew-Eurodrive(china) holding Co., LTD., Suzhou, China
}

\begin{abstract}
This paper analyses the harmonic pollution to power grids caused by several high-power rectifiers, summarizes the requirements for rectifiers in suppressing grid-side current harmonics and optimizes a new-type of current source PWM rectifier with a hybrid switch. The rectifier with a hybrid switch boasts significant current characteristics and cost advantages in the high-power area. To further enhance the working frequency of the current source rectifier with a hybrid switch for suppressing grid-side harmonics and reducing the inductance size, this paper proposes an optimal control strategy based on space vector. It also verifies that the optimal control strategy based on space vector can reduce the total harmonic distortion of the grid-side current of the rectifier with a hybrid switch via circuit simulation and experimental results.
\end{abstract}

Key words: Grid-side current harmonics, Hybrid switch, Space vector modulation

\section{INTRODUCTION}

Due to the action of high-power electronic devices and the influence of reactive components, when a traditional high-power rectifier takes electricity from a power grid, a lot of harmonic currents are injected into the power system. Thus the harmonic level of the power grid is growing higher and higher on an annual basis. These harmonics pose some serious threats to other equipment drawing electricity from the power grid, such as local harmonic resonance, active loss increases, overheating and damage to shunt capacitors, metering errors, and errors in relay protection device operation. Owing to its simple circuit and easy control, the high-power diode rectifier is widely used. However, the

Manuscript received Apr. 24, 2014; accepted Aug. 5, 2014

Recommended for publication by Associate Editor Marian P. Kazmierkowski.

†Corresponding Author: njupt-xuyan@163.com

Tel: +86-139-5204-0432, Southeast University, China

* Department of Electrical Engineering, Southeast University, China

*** Monlithicpower System Inc., China

${ }^{* * *}$ sew-Eurodrive(china) holding Co.,LTD., China output power cannot be controlled and with changes of the DC-side inductance, for the grid-side current harmonics, the total harmonic distortion (THD) will be $30 \%$ or above, while the THD will reach $230 \%$ or more when the inductance diminishes. Another rectifier commonly used in industry is the silicon-controlled phase-shifting rectifier bridge, whose output-side voltage can be regulated by controlling the phase angle of the thyristor. However, this introduces the problem of reactive power and a quite serious current distortion. To eliminate the interference of high-power converters on a power grid, two methods can be adopted. First, add a filter to provide pathways for the harmonic currents. This reduces the influence of harmonic currents over other electrical equipment. The other method, which is more effective, is to increase the number of rectification phases, namely increasing the number of the pulses of rectified voltage. The $\Delta-Y$ dual rectifier bridge (12-pulse rectifier circuit) can make the primary-side current of the power frequency transformer closer to a sine wave by superposing two winding currents on the AC-side. Thus, the grid-side harmonic current component 


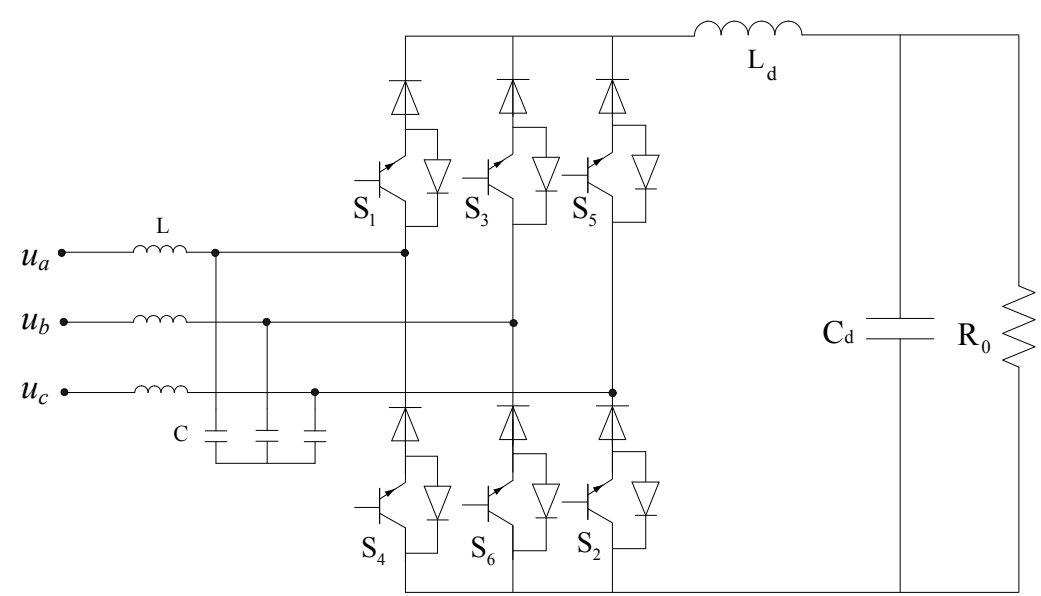

Fig. 1. Traditional 3-phase PWM current source rectifier.

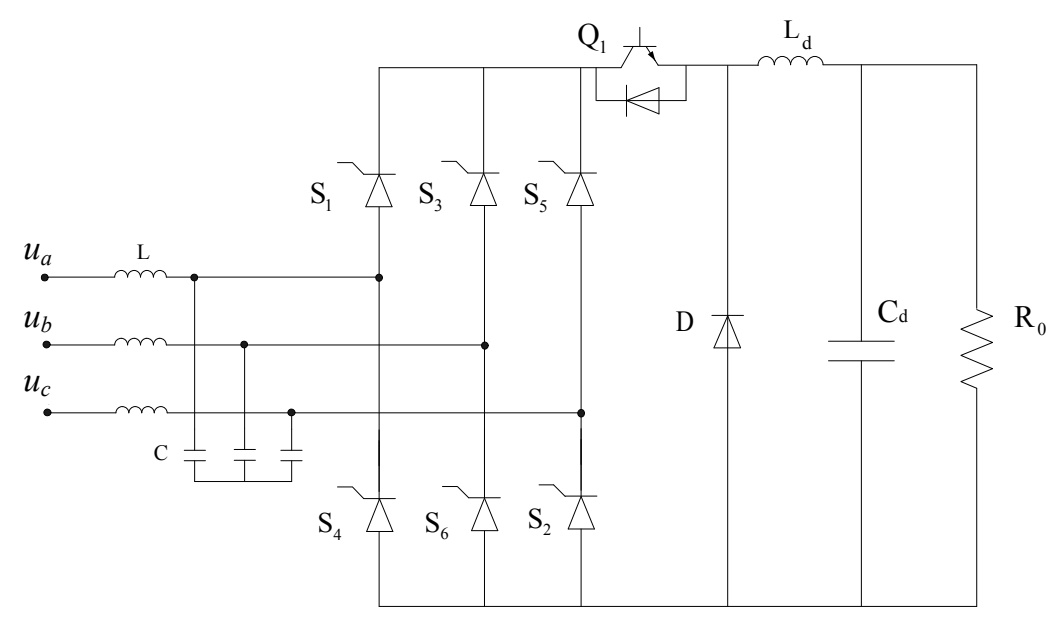

Fig. 2. 3-phase PWM current source rectifier with hybrid switch.

is greatly reduced, and the harmonic frequency with the lowest order is the 11th harmonic, whose amplitude takes up only $1 / 11$ of the amplitude of the fundamental harmonic. In addition, the THD of harmonics is less than $11 \%$. However, the complex power frequency transformer of the circuit increases the cost and size of the entire system [1], [2].

The grid-side current or voltage is modulated into a high-frequency PWM pulse wave by a three-phase PWM rectifier. After filtering the high frequency harmonics of the grid-side current, the grid-side harmonic distortion rate can fully reach national safety standards. Fig. 1 shows a three-phase current source PWM rectifier, where the circuit is realized via controllable high-frequency switch valves with high a tolerance under high power, such as IGBT, IGCT and IECT. However, these valves cost too much money and for the latter two, only a small number of companies are able to produce them at present.

The three-phase current-mode PWM rectifier with a hybrid switch is as shown in Fig. 2, where the output voltage of the circuit has the voltage drop characteristic; the grid-side current harmonic component is small; the high inductance on the output side of the circuit increases the circuit stability and safety; and the use of a thyristor provides cost advantages for the circuit. The circuit can be applied to motor drive and metal heat treatment industries [3]-[5].

\section{CiRCUIT TOPOLOGY}

When compared with traditional three-phase current source PWM rectifiers, the rectifier with a hybrid switch has the following features: it uses six thyristors to replace the six IGBTs at the rectifier bridge; it uses an IGBT with the main switch tube to make a connection with rectifier bridge in series. This forces the IGBT to switch off the turn-on thyristor of the rectifier bridge. Thus, the thyristor rectifier bridge has the ability of pulse width modulation. Since the thyristor has no limitation on the latching effect, the current characteristic is far better, and the forward voltage drop is smaller than that of the controllable switch valve with the same power level, which improves the entire circuit efficiency [4], [5].

However, after the IGBT with the main switch tube is switched off, the thyristor requires a relatively long period to recover from the turn-on to the forward blocking state. This seriously restricts the working frequency of the circuit. To enhance the working frequency of the circuit for reducing the 


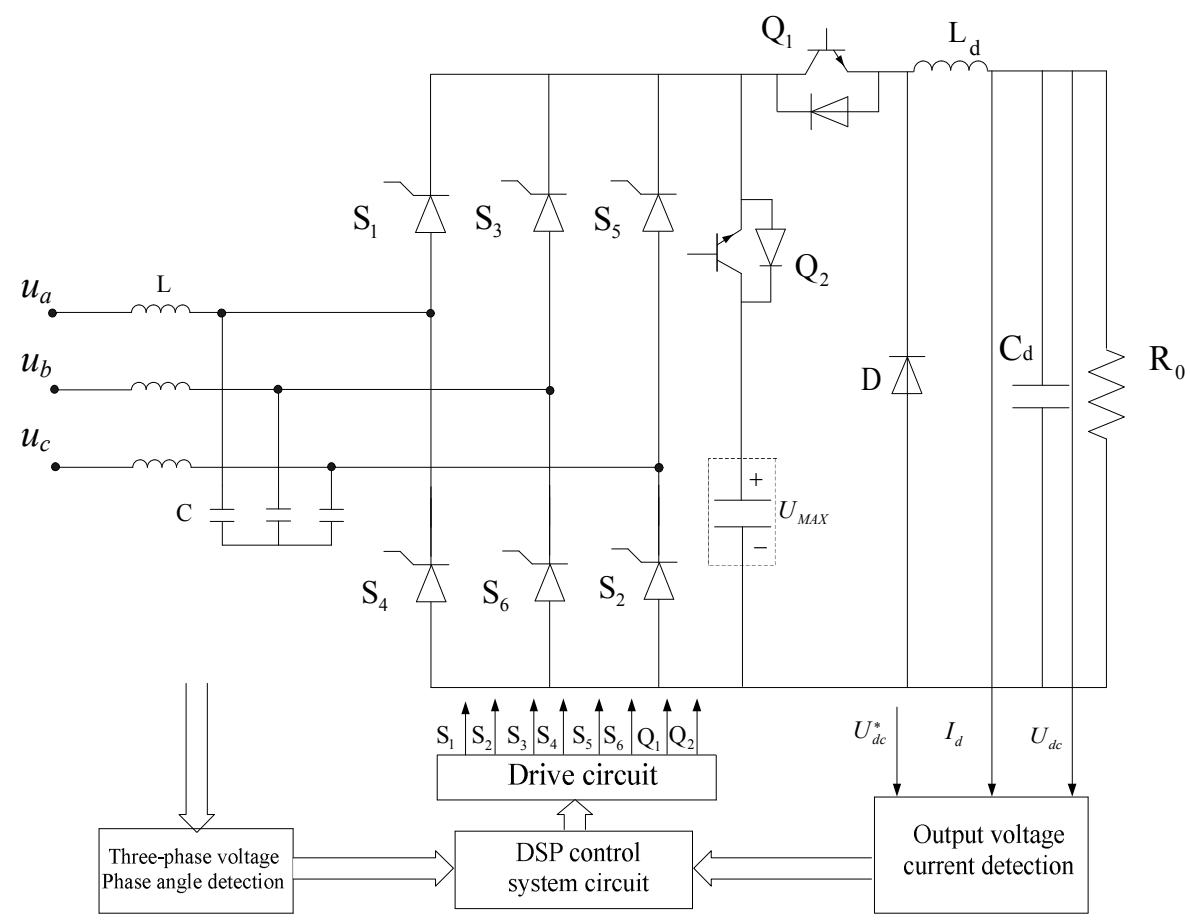

Fig. 3. Advanced 3-phase PWM current source rectifier in addition with reverse voltage source and control system.

volumes of the filter elements on the AC-side and DC-side and to make it easier to filter harmonics, it is necessary to shorten the recovery time, $\mathrm{T}_{\mathrm{OFF}}$, of the thyristor after its switching-off, or to increase the thyristor switching-off time distributed by the circuit. To shorten $\mathrm{T}_{\mathrm{OFF}}$, it is acceptable to provide reverse voltage for the turn-on thyristor to speed up the reverse recovery process. The hybrid switch circuit after being added with the reverse voltage circuit is shown in Fig. 3. Since the reverse voltage network only needs to supply the thyristor with reverse recovery current, the switch valves for ordinary power levels can already meet the requirements for $\mathrm{Q}_{2}$. The voltage source, $\mathrm{U}_{\max }$, supplying reverse voltage is obtained through the boost transformer's enhancing the grid-side voltage, rectification via the common diode rectifier bridge, and final filtering of the voltage-stabilizing capacitance [5]-[7].

\section{StRATEGY FOR THE CONTROL OF CURRENT SOURCE SPACE VECTORS}

The three-phase current source PWM rectifier with a hybrid switch in this paper is realized by space vector control (SVPWM). Fig. 4 shows the current vectors of the three-phase current source rectifier and its axis. For SVPWM modulation, the nine current vectors in Fig. 4 are used to synthesize the required reference current vector, I* [6], [7].

In the current source space vector control method, a reference vector $\mathrm{I}^{*}$ is given, as shown in Fig. 4, which can be synthesized by $\mathrm{I}_{1}$ and $\mathrm{I}_{6}$ based on the following formulas.

$$
T_{s} I^{*}=T_{1} I_{1}+T_{6} I_{6}
$$

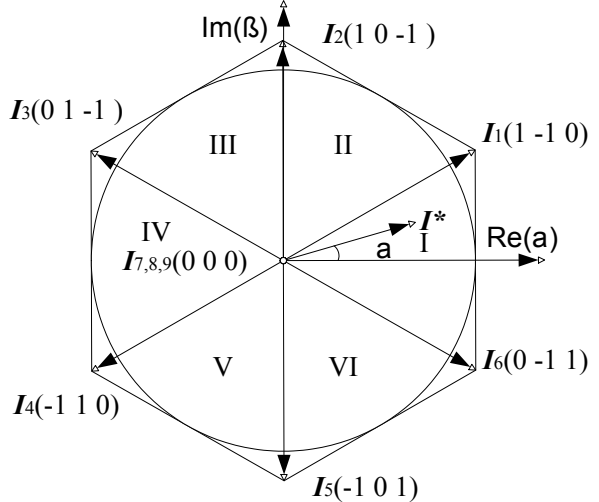

Fig. 4. Current vectors of a three-phase current-mode rectifier.

$$
\begin{gathered}
T_{1}=\frac{\left|I^{*}\right|}{I_{d}} T_{s} \sin \left(\frac{\pi}{6}+\alpha\right)=m T_{s} \sin \left(\frac{\pi}{6}+\alpha\right) \\
T_{6}=\frac{\left|I^{*}\right|}{I_{d}} T_{s} \sin \left(\frac{\pi}{6}-\alpha\right)=m T_{s} \sin \left(\frac{\pi}{6}-\alpha\right) \\
T_{0}=T_{s}-T_{1}-T_{6}
\end{gathered}
$$

Where, $\mathrm{I}_{\mathrm{d}}$ is the dc side current; $\alpha$ is the initial phase angle of $\mathrm{I}^{*} ; \mathrm{T}_{1}, \mathrm{~T}_{6}$ and $\mathrm{T}_{0}$ are the acting times of $\mathrm{I}_{1}, \mathrm{I}_{6}$ and $\mathrm{I}_{7}$, respectively; $\mathrm{T}_{\mathrm{s}}$ is the switching period; and $\mathrm{m}$ is the modulation ratio. From formulas (1) to (4), the acting time $\mathrm{T}_{0}$ of the zero vector can be obtained. As shown in Fig. $5, \mathrm{I}_{7}$ is distributed equally between $I_{1}$ and $I_{6}$, and the switching-off time provided for the thyristor is $T_{0} / 2$. The highest working frequency $f_{\mathrm{S}}$ of the circuit is determined according to Formula (5) [7], [11]. 


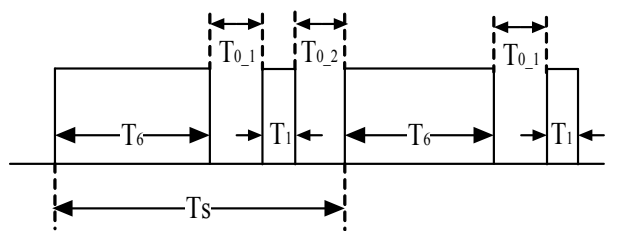

Fig. 5. Sequence diagram of various vectors in SVPWM.

$$
f_{s(\max )}=\frac{1-m_{(\max )}}{2 T_{\mathrm{OFF}}}
$$

\section{OPTIMAL STRATEGY FOR CONTROL OF CURRENT SOURCE SPACE VeCTORS}

To increase the thyristor switching-off time distributed by the control system, the specific switching process of the circuit will be analyzed as follows. As shown in Figure 4, in Sector I, when $-\pi / 6<\alpha<0$, the grid-side capacitor voltage $\mathrm{U}_{\mathrm{A}}<\mathrm{U}_{\mathrm{C}}$. There are two cases [8], [11]:

1) $S_{1}$ switches off to commutate, and $S_{5}$ switches on. If $S_{1}$ has not gone back to the forward blocking state, the valve voltage of $\mathrm{S}_{5}$ is positive. In this case, $\mathrm{S}_{5}$ is provided with a gating pulse and opens naturally under a positive voltage, while $S_{1}$ is forced to switch off under a negative voltage. Thus, theoretically, the time T0_1 for $S_{1}$ 's commutation to $S_{5}$ can be 0 .

2) $S_{5}$ switches off to commutate, and $S_{1}$ switches on. If $S_{5}$ still has not gone back to the switching-off state, the valve voltage of $S_{1}$ undertakes a negative voltage. In this case, $\mathrm{S}_{5}$ cannot be opened after being provided with a gating pulse when the $S_{5}$ valve's commutation to the $S_{1}$ valve fails. Therefore, the time $\mathrm{T}_{0} 2$ for $\mathrm{S}_{5}$ 's commutation to $\mathrm{S}_{1}$ shall at least meet $\mathrm{T}_{\mathrm{OFF}}$.

However, for the case of $\mathrm{U}_{\mathrm{A}}=\mathrm{U}_{\mathrm{C}}$, this can be avoided by setting a specific switching frequency, which can ensure that the above two cases exist when commutation. To achieve this, make sure the required recovery time of the thyristor under the condition of non-natural commutation is $\mathrm{T}_{\mathrm{OFF}}$; put the acting time of the remaining zero vectors before that of the vectors with natural commutation. This can ensure the normal commutation of the thyristor in the circuit, which achieves the normal conduction of the current space vectors. The minimum zero vector time of the circuit can be $\mathrm{T}_{\mathrm{OFF}}$ and the highest working frequency of the circuit is determined by Formula (6) [9]-[11]:

$$
f_{s}=\frac{1-m}{T_{\mathrm{OFF}}}
$$

Let the switching-off time $\mathrm{T}_{\mathrm{OFF}}$ of the thyristor be $41.67 \mu \mathrm{s}$ and the maximum modulation ratio $\mathrm{m}$ be 0.9 . Then, according to Formula (5) of the traditional current source space vector control, the working frequency of the circuit is $1.2 \mathrm{kHz}$; and according to Formula (6) of the optimal current source space vector control, the value is $2.4 \mathrm{kHz}$. Under the condition of

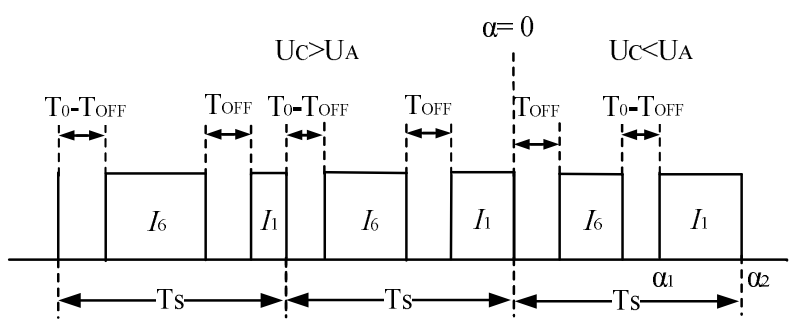

Fig. 6. Sequence diagram of vectors in Sector I of an optimal SVPWM.

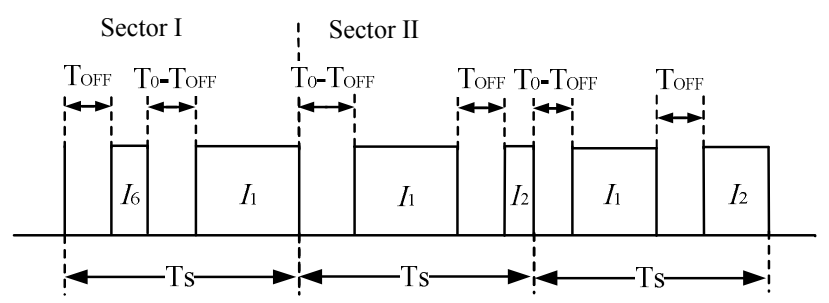

Fig. 7. Sequence diagram of vectors from Sector I to Sector II of an optimal SVPWM.

optimal space vectors, see the sequence diagram of various vectors in a sector (as shown in Fig. 6) and take Sector I as an example.

As shown in Fig. 6, in the switching period $\left(0<\alpha \leq \alpha_{2}\right)$ after $\alpha=0$, the reserve voltage value of the thyristor $\left(\alpha=\alpha_{1}\right)$ is at its minimum when the forced commutation happens. In $0<\mathrm{a} \leq \alpha_{2}$, this can be calculated from Formula (7),

$$
\left\{\begin{array}{c}
T_{1}=m T_{S} \sin \left(\frac{\pi}{6}+0\right) \\
\alpha_{1}=\frac{T_{S}-T_{1}}{20 m s} \times 2 \pi
\end{array}\right.
$$

For $\mathrm{m}=0.9$ and $\mathrm{T}_{\mathrm{S}}=416.7 \mu \mathrm{s}$, it is possible to obtain $\alpha_{1} \approx 0.072$, which is then substituted into Formula (8),

$$
U_{A C}=U_{A}-U_{C}=U_{S} \sin \left(\frac{\pi}{6}+\alpha_{1}\right)-U_{S} \sin \left(\frac{\pi}{6}+\alpha_{1}+\frac{2 \pi}{3}\right)
$$

From the peak value of the grid-side phase voltage $\mathrm{U}_{\mathrm{S}} \approx 311 \mathrm{~V}$, it is possible to obtain $\mathrm{U}_{\mathrm{AC}} \approx 38.75 \mathrm{~V}$. By this calculation, it is possible to obtain the minimum reverse voltage, which is about $38.75 \mathrm{~V}$, in the forced commutation of the thyristor. This theoretically meets the condition of adding reverse voltage to the switch off thyristor [11], [12].

In addition, considering the commutation among the sectors, Fig. 7 shows a diagram of the vector distribution from Sector I to Sector II. In Fig. 7, for the non-natural commutation, the switching-off time of the thyristor required to be switched off is $\mathrm{T}_{\mathrm{OFF}}$; for the natural commutation, the reverse voltage imposed on the thyristor to be switched off is far greater than the minimum, $38.75 \mathrm{~V}$. In other words, it can ensure normal conduction of the current source space vectors of the circuit. This is validated by simulation and experiment in the following sections [10]-[15]. 


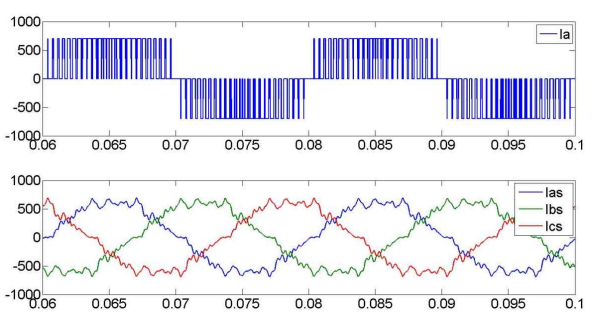

Fig. 8. Grid-side current waveform under the optimal control strategy.

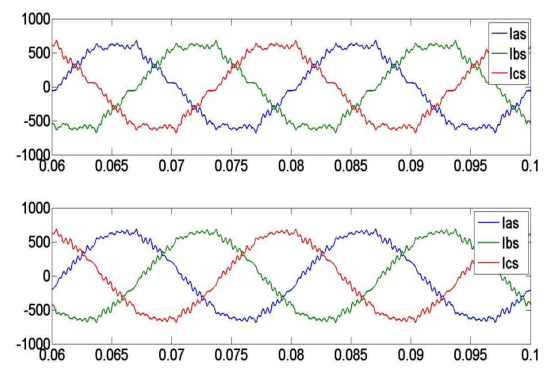

Fig. 9. Grid-side current waveform. (a) Grid-side current waveform after absorption of the $13^{\text {th }}$ harmonic. (b) Grid-side current waveform after absorption of the $13^{\text {th }}$ and $19^{\text {th }}$ harmonics.

\section{SimULATION RESULtS}

A Simulink verification is conducted for the optimal space vector method control strategy of the three-phase current-mode PWM rectifier with a hybrid switch. For the simulation, the power is $280 \mathrm{~kW}$, the working direct current is $700 \mathrm{~A}$, the grid-side filter's resonance frequency is about $750 \mathrm{~Hz}$, the $\mathrm{AC}$ inductance of the three-phase filter is $125 \mu \mathrm{H}$, the equivalent series resistance is $0.05 \Omega$, the grid-side three-phase filter capacitance is $360 \mu \mathrm{F}$, the quality factor of the filter is about 10 , and the working frequency of the circuit is $2.4 \mathrm{kHz}$. Fig. 8 shows the grid-side current waveform.

(a) Grid-side PWM current waveform of Phase a before filtering; (b) Grid-side current waveform of various phases after filtering

For the Fourier analysis of the grid-side current, shown in Fig. 8(b), the THD of the grid-side current Isa is approximately $19.53 \%$. This current mainly contains the $13^{\text {th }}$ and $19^{\text {th }}$ harmonics, which account for around $15.07 \%$ and $7.85 \%$ of the fundamental component, respectively. This is due to the vector distribution. As shown in Fig. 6, vector $I_{6}$ is distributed continuously around $\alpha=0$, which leads to grid-side current distortion. After filtering the $13^{\text {th }}$ and $19^{\text {th }}$ harmonics of the power grid by adding a resonance absorption circuit, the grid-side three-phase current waveform is changed as shown in Fig. 9 [11], [14].

In Fig. 9(a), after filtering the $13^{\text {th }}$ current harmonic, the THD of the grid-side current Isa is about $12.3 \%$. In Figure 9(b), after simultaneous resonance absorption of the $13^{\text {th }}$ and $19^{\text {th }}$ current harmonics, the THD of the grid-side current Isa is around $9.60 \%$.

Compared with the traditional current source space vectors,

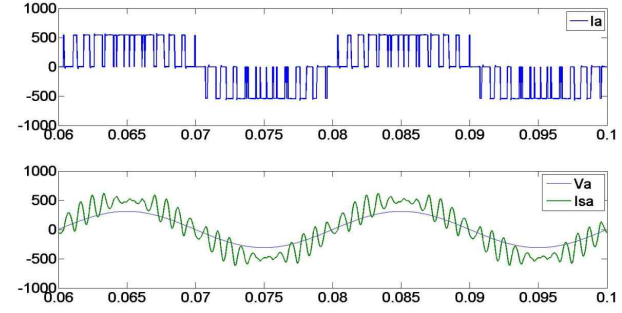

Fig. 10. Grid-side current waveform under the traditional control strategy. (a) Grid-side PWM current waveform of Phase a before filtering. (b) Grid-side current and voltage waveforms of Phase a after filtering.

TABLE I

RESUltS FOR HARMONIC ANALYSIS OF GRID-SIDE CURRENT WITH ADVANCED CONTROL METHOD

\begin{tabular}{|c|l|l|l|l|l|l|}
\hline$n$ & 5 & 11 & 17 & 19 & 49 & 53 \\
\hline$I_{n} / \%$ & 4.87 & 4.97 & 7.06 & 2.97 & 3.18 & 2.64 \\
\hline
\end{tabular}

TABLE II

RESULTS FOR HARMONIC ANALYSIS OF LINE CURRENT WITHOUT ADVANCED CONTROL METHOD

\begin{tabular}{|r|l|l|l|l|l|l|}
\hline$n$ & 14 & 16 & 20 & 22 & 26 & 28 \\
\hline$I_{n} / \%$ & 2.20 & 3.74 & 10.8 & 26.9 & 15.6 & 3.44 \\
\hline
\end{tabular}

with the same thyristor switching-off time and circuit modulation ratio, the highest working frequency of the circuit is $1.2 \mathrm{kHz}$. When using the same circuit topology parameters for the simulation, the grid-side current waveform will be as shown in Fig. 10. Since the corner frequency of the grid-side filter is very close to the working frequency of the circuit, the harmonics of the switching frequency and its marginal frequency are not easy to filter. Upon using the Fourier analysis, it can be seen that the amplitude of the switching frequency harmonic in the grid-side current Isa takes up about $27.88 \%$ of the fundamental harmonic, while the THD of the grid-side current Isa is around $34.3 \%$. In addition, it is impractical to absorb the harmonic of the switching frequency by adding resonance absorption current. It is only feasible to attenuate the harmonics by adding a filter to the main circuit. However, this increases the cost and size of the whole circuit [10]-[12].

Judging by the simulation results, improving the switching frequency by using the optimal current source space vector control will cause certain grid-side current distortions. However, by adopting a resonance absorption circuit, it is possible to suppress the grid-side current harmonics, while the traditional space vector control methods cannot achieve an equivalent harmonic suppression effect.

\section{EXPERIMENT RESULTS}

To validate the above-analyzed three-phase current source PWM rectifier with a hybrid switch as well as its PWM rectification control method and principle, a low-power 


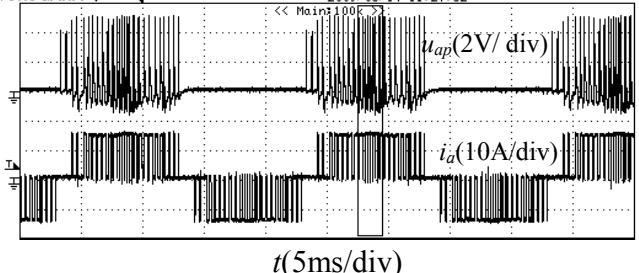

(a)

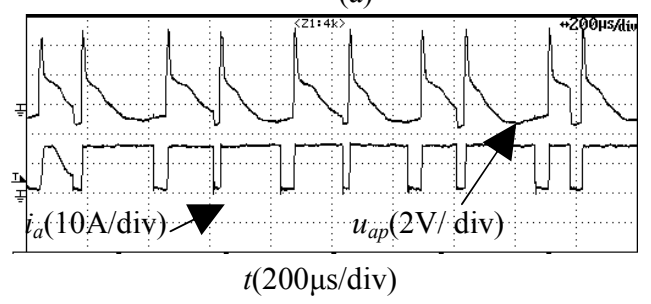

(b)

Fig. 11. Current waveforms under the optimal control strategy. (a) Drive pulse of upper tube and PWM current waveform of Phase a. (b) Drive pulse of upper tube and PWM current waveform of Phase a after amplifying.

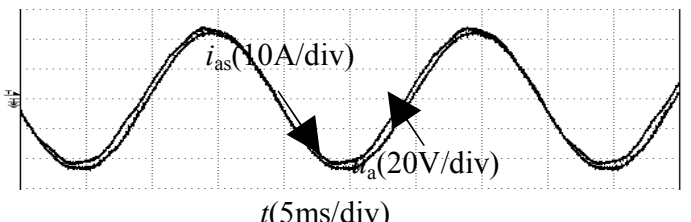

Fig. 12. Grid-side current $i_{\text {as }}$ and voltage waveform $u_{\text {as }}$ of Phase a

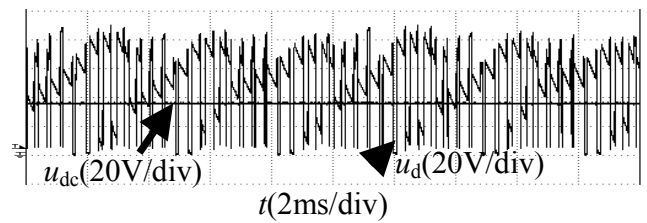

Fig. 13. Output voltage $u_{\mathrm{d}}$ of rectifier and filtered DC-side voltage $u_{\mathrm{dc}}$

test prototype has been designed. The main circuit parameters for the experiment are as follows: IGBT modules are used for $\mathrm{T}_{1}, \mathrm{~T}_{2}$; a common thyristor is used for the rectifier, with the switching-off time set as the minimum value of $42 \mu \mathrm{s}$; the grid-side filter capacitance is $126.6 \mu \mathrm{F}$; the filter inductance is $1 \mathrm{mF}$; the DC-side filter inductance is $1 \mathrm{mH}$; the capacitance is $2 \mathrm{mF}$; the load current is $15 \mathrm{~A}$; the working frequency of circuit is $2.4 \mathrm{kHz}$; and the amplitude of the modulation ratio is 0.85 . The digital control system is based on a DSP chip (TMS320LF28335) [11], [15].

Fig. 11(a) shows the drive pulse of the upper tube of Phase $A$ and the PWM current waveform of Phase A, which are enlarged in the circle of Fig. 11(b). After the minimum zero vector time, $20 \mu \mathrm{s}$ of a cycle, the common thyristor can be realized via the forced commutation. This validates the feasibility of the optimal current source space vector strategy.

Fig. 12 shows the grid-side current and grid-side voltage waveform of Phase A after filtering. It can be seen that the
THD of the grid-side current is $3.5 \%$. It can also be seen that the grid-side current and voltage are of the same phase, and that the current waveform is basically a sine wave. Fig. 13 shows the voltage waveform output of the DC-side rectifier bridge and that after the filter inductance. It can be seen that the enhancement of the circuit switching frequency can greatly reduce the cost and size of the DC filter [11], [12], [15].

\section{CONCLUSION}

This paper analyzes the influence of high-power rectifiers on power grids, and introduces a method for eliminating the interference of power grids by high-power converters. Specifically, a three-phase current source PWM rectifier with a hybrid switch that uses a thyristor to replace the high-power controllable switch tube to make a low cost high-power PWM rectifier. While guaranteeing thyristor switching-off, the use of the optimal space vector control method also enhances the working frequency of the circuit, and ensures that the grid-side current harmonics can be better suppressed. Moreover, this paper analyzes both the advantages and disadvantages of the optimal control method by system simulation. The proposed method makes the grid-side current harmonics of the rectifier greatly suppressed via circuit optimization. Finally, the feasibility of the three-phase current source PWM rectifier with a hybrid switch and the correctness of the optimal current source space vectors are validated by experimental results.

\section{REFERENCES}

[1] G. Gong, M. L. Heldwein, U. Drofenik, , J. Minibock, K. Mino, and J. W. Kolar, "Comparative evaluation of three-phase high-power-factor AC-DC converter concepts for application in future More Electric Aircraft," IEEE Trans. Ind. Electron., Vol. 52, No. 3, 727-737, Jun. 2005.

[2] M. Salo and H. Tuusa, "A vector controlled current- source PWM rectifier with a novel current damping method," IEEE Trans. Power Electron., Vol. 15, No. 3, pp. 464-470, May 2000.

[3] C. Zhang, H. Gu, and B. Wang, "Mathematical model of three-phase PWM rectifier based on a novel phase and amplitude control," in Proc. the CSEE, Vol. 23, No. 7, pp. 28-31, 2003.

[4] M. Malinowski, M. Jasin'ski, and M. P. Kazmierkowski, "Simple direct power control of three-phase pwm rectifier using space-vector modulation," IEEE Trans. Ind. Electron., Vol. 51, No. 2, pp. 447-454, Apr. 2004.

[5] Y. Li, H. Li, and Y. Peng, "Research on multi-level technique of three-phase current source SVPWM rectifier based on vector synthesis scheme." in Proc. the CSEE, Vol. 27, No. 31, pp. 104-109, 2007.

[6] J. Dannehl, C. Wessels, and F. W. Fuchs, "Limitations of voltage-oriented PI current control of grid-connected PWM rectifiers with LCL filters," IEEE Transactions on Industrial Electronics, Vol. 56, No. 2, pp. 380-388, Feb. 2009. 
[7] B. Geethalakshmi, P. Sanjeevikumar, and P. A. Dananjayan, "PWM current source rectifier with leading power factor," International Conference on Power Electronics, Drives and Energy Systems for Industrial Growth, 2006.

[8] A. Bouafia, J. P. Gaubert, and F. Krim, "Predictive direct power control of three-phase pulsewidth modulation rectifier using space-vector modulation," IEEE Trans. Power Electron., Vol. 25, No. 1, pp. 228-236, Jan. 2010.

[9] Y. Zhong and S. Shen, "Decoupled control and DSP implement of PWM rectifier," in Proc. the 5th World Congress on Intelligent Controland Automation, pp. 5199-5202, 2004.

[10] I. Wallace, A. Bendre, J. P. Nord, G. Venkataramanan, “A unity power factor three phase PWM SCR rectifier for high power applications in the metal industry," IEEE Trans. Ind. Appl., Vol. 38, No. 4, pp. 968-975, Jul./Aug. 2001 .

[11] L. Jiang, Z. Cai, Z. Lü, "Research on the improved 3-phase PWM current source rectifier with hybrid switch," Power Electronics and Motion Control Conference, 2009.

[12] Y. Li, Y. Peng, and H. Li, "Over-modulation technique of three-phase current source rectifier based on FPGA," Conference on Industrial Electronics and Applications, 2007.

[13] F. Briz, M. W. Degner, and R. D. Lorez, "Analysis and design of current regulators using complex vectors," IEEE Trans. Ind. Appl., Vol. 36, No. 6, pp. 817-825, May/Jun. 2000.

[14] C. Zhuojian, L. Jiang, R. Zhao, and H. Chen, "A hybrid three phase current source rectifier for high power application," Power Electronics and Motion Control Conference, 2009.

[15] X. Jian, Z. Kai, and C. Jian, "An engineering design technique of PWM rectifier," Adavanced Technology of Electrical Engineering and Energy, Vol. 21, No. 3, pp. 44-48, 2002.

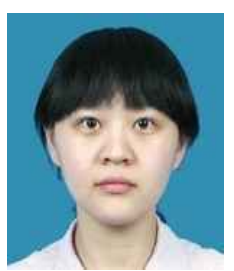

Yan Xu received her B.S. and M.S. degrees in Optical Communication from the Nanjing University of Posts and Telecommunications, Nanjing, China, in 2004 and 2011, respectively, where she is presently working toward her Ph.D. degree. Her current research interests include micro-grid power quality, electric power savings, and relay

protection.

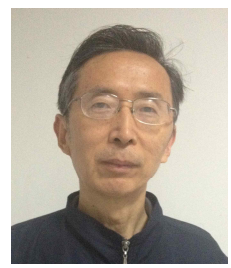

Guang-xiang Lu was born in Jiangsu, China, on October 3, 1956. He received his B.S., M.S. and Ph.D. degrees in Electrical Engineering from Southteast University, Nanjing, China, in 1982, 1991 and 2000, respectively. He is presently a Professor in the Department of Electrical Engineering, Southteast University. His current research interests include micro-grid power quality, electric power savings, and relay protection.

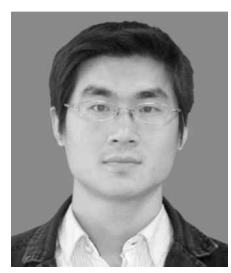

Li-jie Jiang was born in Chongqing, China, on May 20, 1983. He received his B.S., M.S. and Ph.D. degrees in Electrical Engineering in 2005, 2008 and 2011, respectively. He is presently working for Monlithicpower System Inc., Hangzhou, China. His current research interests include power electronic digital control and system

integration.

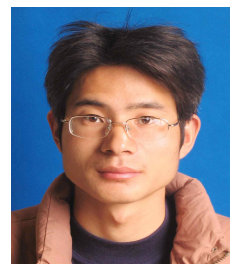

Gui-Ping Yi received his B.S. degree from the College of Electrical and Information Engineering, Nanchang University, Nanchang, China, in 2004, and his M.S. degree from the College of Electric Power and Automation Engineering, Shanghai University of Electric Power, Shanghai, China, in 2010. He is presently working toward his Ph.D. degree. His current research interests include micro-grid power quality, electric power savings, reactive power compensation, and active power filters. 